\title{
The epidemiology of eating disorders in six European countries: Results of the ESEMeD-WMH project
}

\author{
Antonio Preti ${ }^{a}$, Giovanni de Girolamo ${ }^{\text {b,* }}$, Gemma Vilagut ${ }^{\text {chh }}$, Jordi Alonso ${ }^{\text {chh }}$, Ron de Graaf ${ }^{\text {, }}$, \\ Ronny Bruffaerts ${ }^{\mathrm{e}}$, Koen Demyttenaere ${ }^{\mathrm{e}}$, Alejandra Pinto-Meza ${ }^{\mathrm{f}}$, Josep Maria Haro ${ }^{\mathrm{f}}$, \\ Piero Morosini ${ }^{\mathrm{g}}$, The ESEMeD-WMH Investigators ${ }^{1}$ \\ a Department of Psychology, University of Cagliari, Cagliari, Italy \\ b IRCCS Centro S. Giovanni di Dio-Fatebenefratelli, Via Pilastroni 4, 20125 Brescia, Italy \\ ${ }^{\mathrm{c}}$ Health Services Research Unit, Institut Municipal d'Investigació Mèdica (IMIM-Hospital del Mar), Barcelona, Spain \\ ${ }^{\mathrm{d}}$ Netherlands Institute of Mental Health and Addiction, Utrecht, The Netherlands \\ e Department of Neurosciences and Psychiatry, University Hospitals, Gasthuisberg, Belgium \\ ${ }^{\mathrm{f}}$ Sant Joan de Deu-SSM, Barcelona, and CIBER en Salud Mental (CIBERSAM), Spain \\ ${ }^{\mathrm{g}}$ Mental Health Unit, Center of Epidemiology, Health Surveillance and Promotion, Italian National Institute of Health, Rome, Italy \\ ${ }^{\mathrm{h}}$ CIBER en Epidemiología y Salud Pública (CIBERESP), Spain
}

\section{A R T I C L E I N F O}

Article history:

Received 16 January 2009

Received in revised form 7 April 2009

Accepted 14 April 2009

\section{Keywords:}

Anorexia nervosa

Bulimia nervosa

Binge eating disorder

Eating disorders

Epidemiology

\begin{abstract}
A B S T R A C T
Few data are available to estimate the prevalence of eating disorders (EDs) and their correlates in the community. This paper reports data on EDs obtained in the framework of the ESEMeD project, aimed at investigating the prevalence of non-psychotic mental disorders in six European countries (Belgium, France, Germany, Italy, the Netherlands and Spain), using a new version of the Composite International Diagnostic Interview. The ESEMeD study was a general population cross-sectional household survey. In total, 21,425 respondents aged 18 or older provided data for the project between January 2001 and August 2003. A subsample $(N=4139)$ underwent a detailed investigation on EDs. Lifetime estimated prevalence of anorexia nervosa, bulimia nervosa, binge eating disorder, sub-threshold binge eating disorder, and any binge eating were $0.48 \%, 0.51 \%, 1.12 \%, 0.72 \%$, and $2.15 \%$, respectively, and they were $3-8$ times higher among women for all EDs. However, since people under 18 were excluded from this study, our prevalence should be taken as lower-bound estimate of real frequencies. Indeed, cumulative lifetime prevalence analysis showed that the majority of eating disorders had their initial onset between 10 and 20 years of age. Role impairment and comorbidity with other mental disorders were highly common, yet only small proportions of patients with a lifetime diagnosis of EDs requested medical treatment. It still has to be proven whether early diagnostic identification and access to specialized care can reduce the burden caused by these disorders.
\end{abstract}

(c) 2009 Elsevier Ltd. All rights reserved.

\section{Introduction}

Current diagnostic classifications recognize two main eating disorders (EDs), anorexia nervosa and bulimia nervosa, with symptomatic variants recorded as a global "not otherwise specified" class (APA, 1994; WHO, 1992). The binge ED has been proposed as a possible additional clinical category (Spitzer et al., 1992). The status of sub-threshold disorders is still debated: several studies have shown that sub-threshold disorders may cause less

\footnotetext{
* Corresponding author. Tel.: +390303501590.

E-mail address: gdegirolamo@fatebenefratelli.it (G. de Girolamo).

1 The ESEMeD-WMH Investigators are: Jordi Alonso, Matthias Angermeyer, Sebastian Bernert, Ronny Bruffaerts, Traolach S. Brugha, Giovanni de Girolamo, Ron de Graaf, Koen Demyttenaere, Isabelle Gasquet; Josep Maria Haro, Steven J. Katz; Ronald C. Kessler, Viviane Kovess, Jean Pierre Lépine, Johan Ormel, Gabriella Polidori, and Gemma Vilagut.
}

impairment and disability than full-blown disorders (Hudson et al., 2007), but other reports seem to indicate some kind of progression of sub-threshold disorders (Patton et al., 1999), therefore representing important antecedents of anorexia and bulimia nervosa.

Few data are available to estimate the prevalence of EDs. Most studies have concentrated on single samples selected at local level, or have investigated symptoms' distribution by means of questionnaires rather than personal interviews (Hoek and Van Hoeken, 2003; Miotto et al., 2003; Vega Alonso et al., 2005). Point prevalence of anorexia nervosa has been reported around $0.3 \%$ in American and European studies (Hoek and Van Hoeken, 2003; Favaro et al., 2004), with lifetime prevalence approximating $0.5-0.6 \%$ in two large population-based surveys in the United State (US) and Canada (Garfinkel et al., 1996; Walters and Kendler, 1995), and reaching $1 \%$ in a very large population survey in the Netherlands 
(Bijl et al., 1998). Lifetime prevalence of bulimia nervosa has been estimated to range between $1 \%$ and $3 \%$ in three large surveys in New Zealand, the US and Canada (Bushnell et al., 1990; Garfinkel et al., 1995; Kendler et al., 1991), but as low as $0.6 \%$ in the Netherlands (Bijl et al., 1998).

Male/female ratios have been found to range from 1:5 to $1: 10$ for both anorexia and bulimia nervosa (Bushnell et al., 1990; Garfinkel et al., 1995, 1996), although one large-scale survey, carried out in a national representative sample of US citizens, found higher prevalence among males than in past studies, resulting in a lower female/male ratio (Hudson et al., 2007). With regard to binge ED, data are sparse, with estimated prevalence around 3.3\% among women and $0.8 \%$ among men in a large-scale population-based survey, conducted with telephone interviews in Austria (Kinzl et al., 1999), and, respectively, $3.5 \%$ and $2.0 \%$ in the US National Comorbidity Replication study (NCS-R) (Hudson et al., 2007).

This paper reports prevalence estimates of EDs obtained in the framework of the European Study of the Epidemiology of Mental Disorders (ESEMeD) project (ESEMeD/MHEDEA 2000 Investigators, 2004a, 2004b), part of the World Mental Health (WMH) Survey initiative, aimed at investigating the prevalence of major mental disorders in six European countries (Belgium, France, Germany, Italy, the Netherlands and Spain), using a new version of the Composite International Diagnostic Interview (CIDI 3.0).

The aims of this study were: (i) to investigate the lifetime and 12-month prevalence of EDs, taking into account three main diagnostic entities (e.g., anorexia nervosa, bulimia nervosa, and binge ED) and two sub-threshold categories (sub-threshold binge ED and binge eating per se); (ii) to describe the major correlates of these diagnostic entities in terms of impairment in role functioning and comorbidity with other mental disorders; and (iii) to assess service use by affected people.

\section{Methods}

\subsection{Sample}

The study was cross-sectional in nature and individuals were assessed in person at their homes using computer-assisted interview (CAPI) techniques. The target population was the non-institutionalized adult population (aged 18 years or older) of Belgium, France, Germany, Italy, the Netherlands and Spain, that is a total of 212,000,000 European citizens. A stratified, multistage, clustered area, probability sample design was used.

In total 21,425 respondents provided data for the project between January 2001 and August 2003. All subjects gave written informed consent for participation after the nature of the procedures had been fully explained, as approved by the Ethical Review Boards of the participating countries. Further description of the sampling frame and selection is provided elsewhere (ESEMeD/MHEDEA 2000 Investigators, 2004b).

The overall response rate in the six countries investigated was $61.2 \%$, with the highest rates in Spain (78.6\%) and Italy (71.3\%), and lower rates in Germany (57.8\%), the Netherlands (56.4\%), Belgium $(50.6 \%)$ and France (45.9\%).

Respondents underwent a detailed interview, based on the version 3.0 of the World Health Organization Composite International Diagnostic Interview (CIDI) (Kessler and Ustun, 2004). For the ESEMeD study, a revised and further enhanced version of the CIDI, was developed and adapted by the Coordinating Committee of the WHO-WMH Survey Initiative (Haro et al., 2006). This version was first produced in English and underwent a rigorous process of adaptation in order to obtain conceptually and cross-culturally comparable versions in each of the target countries and languages. This process included forward and backward translations, a review by a panel of experts, pretesting using interview and debriefing techniques and the conduct of focus groups.

A two-phase interview procedure was used. The first phase contained the diagnostic assessment of the most common mood and anxiety disorders, health-related quality of life, health services utilization and main demographic characteristics. Those who exceeded a predetermined number of symptoms of specific mood or anxiety disorders, and a random $25 \%$ of the rest, received the second phase questionnaire (part 2 respondents, $N=8796$ ), which included an in-depth interview about additional mental disorders, like PTSD, and correlates, amongst other information. The full diagnostic algorithms, and the corresponding CIDI questions used to operationalize the criteria are available online at www.hcp.med. harvard.edu/ncs.

The analyses reported here were carried out in sub-sample part-2 respondents $(N=4139)$, who were randomly selected to undergo an assessment of EDs.

Individuals were weighted to adjust for the differential probabilities of selection for the second phase and differential probabilities within household. Additional post-stratification weights were applied to restore age and gender distribution of the population within each country and the relative population size of the participating countries.

\subsection{Diagnostic instruments}

Diagnoses were based on version 3.0 of the World Health Organization Composite International Diagnostic Interview (CIDI 3.0), a fully structured lay administered diagnostic interview that generates diagnoses according to both the ICD-10 and DSM-IV criteria (Haro et al., 2006; Kessler and Ustun, 2004). DSM-IV criteria were used in the current report (APA, 1994).

\subsubsection{Assessment of EDs}

However, some adaptations were used in the diagnostic process: for binge eating episodes in bulimia nervosa and binge ED, DSM-IV requires the presence of loss of control, and for binge ED requires a marked distress regarding binge eating; these items were assessed in the CIDI 3.0 by a series of questions about attitudes and behaviours that are indicators of loss of control and distress, rather than by direct questioning about loss of control and marked distress during binge eating.

The full diagnostic algorithms for all three disorders are available at www.hcp.med.harvard.edu/ncs/diagnosis.php; the corresponding CIDI questions used to operationalize the criteria are available online at www.hcp.med.harvard.edu/ncs.

We also defined 2 provisional entities. The first was "subthreshold binge ED”, defined as (a) binge eating episodes, (b) occurring at least twice a week for at least 3 months, and (c) not occurring solely during the course of anorexia nervosa, bulimia nervosa, or binge ED. Therefore, sub-threshold binge ED did not require DSM-IV criterion B (e.g., 3 of 5 features associated with binge eating, such as eating more rapidly than normal, eating until being unpleasantly full, eating great quantity of food even without being hungry, eating in solitude due to embarrassment, feeling guilty or disgusted by themselves after the binge) or C (e.g., marked distress regarding binge eating for binge $\mathrm{ED}$ ). The second was "any binge eating", also defined as (a) binge eating episodes (again, not requiring DSM-IV criteria B and C), (b) occurring at least twice a week for at least 3 months, but (c) lacking the hierarchical exclusion criterion if the individual simultaneously exhibited another ED. In other words, any binge eating was diagnosed regardless of whether or not the individual simultaneously met criteria for any of the other 3 EDs or for sub-threshold binge ED. This entity therefore included all cases of bulimia nervosa, binge ED, and sub-threshold binge ED, as well as cases of anorexia nervosa with binge eating. 
Its should be reminded that "any binge eating" is not a specific diagnostic entity: however the investigation of genetic correlates of EDs can greatly benefit from data at a phenotype level, and binge eating, per se, has been demonstrated to be a feature of ED with a large genetic component (Reichborn-Kjennerud et al., 2004). In addition, EDs involving binge eating were found discontinuous with normalcy (Williamson et al., 2005): therefore their identification as a separate entity is justified.

We used data from the CIDI 3.0 regarding time of onset and recency (i.e., the time when the disorder was last present) to apply diagnostic hierarchies, so that bulimia nervosa, binge ED, and sub-threshold binge ED were not diagnosed in the presence of anorexia nervosa; and so that binge ED and sub-threshold binge ED were not diagnosed in the presence of bulimia nervosa.

On the other hand, we were unable to assess diagnostic crossover, a relatively frequent occurrence in EDs (Eddy et al., 2008; Tozzi et al., 2005), since multiple episodes of EDs, including the passage from anorexia nervosa to bulimia nervosa, could not be properly addressed with hierarchical algorithms.

\subsubsection{Short-term impairment}

For individuals meeting criteria for any of the five disorders, the CIDI 3.0 assessed: age of onset, recency, years with the disorder, and professional help-seeking.

Respondents were additionally administered a modified version of the WHODAS-II (the WHODAS-II for the WMH surveys) (BuistBouwman et al., 2006; Chwastiak and Von Korff, 2003; Von Korff et al., 2008), an instrument that evaluates five domains of functioning due to problems with either physical health, mental health, or use of alcohol or drugs (Understanding and communicating; SelfCare, Getting Around, Getting Along with Others, and Life Activities) over a 30-day recall period, and also were asked about lifetime treatment, and treatment in the past 12 months. Cut-off point for severe impairment was defined as the $90 \%$ in the Global Scale in the overall sample.

\subsubsection{Service use}

The use of services was assessed by asking all ESEMeD respondents about past year service use for any problems with emotions, nerves, or substance use by a psychiatrist, any other mental health professional (e.g., clinical psychologist, psychiatric social worker), a general medical health care provider, a non-medical professional (e.g., religious counsellor, a social worker seen in at a social services agency), and in the complementary-alternative medicine (CAM) sector (either participation in a self-help group or treatment by a CAM professional).

\subsection{Statistical analyses}

Lifetime and 12-month prevalence of EDs, comorbidity with other mental disorders, disability and use of services were assessed with cross-tabulations. The actuarial method was used to estimate age of onset curves for each ED (Cox and Oakes, 1984). Discretetime survival analyses with person-years as the unit of analysis using logistic regression were used to evaluate cohort differences (Singer and Willett, 1993). Logistic regression models were carried out to estimate the association (odds ratios) between each ED and individual comorbid conditions; all reported ORs were adjusted by age and sex.

The analysis for this paper was performed with SAS/STAT software, Version 9.0 of the SAS System for Windows (Copyright (C) 2002-2003 SAS Institute Inc. Cary, NC, USA), and SUDAAN v9.0.1 (Research Triangle Institute, 2004), a statistical software used to analyze data from complex sample surveys. Standard errors (SE) and significance tests were estimated using the Taylor series linearization method (LaVange et al., 1996), a design-based method implemented in SUDAAN. Multivariate significance was evaluated using Wald $\chi^{2}$ tests based on design-corrected coefficient variance-covariance matrices. Statistical significance was evaluated by using two-sided design-based tests, with an alpha level of 0.05 .

Missing values of the items used to assess the presence of EDs were imputed with Multiple Imputation, using the MI procedure implemented in SAS and with five imputations (Little and Rubin, 1987). The analysis is then performed with SUDAAN V9.0.1, which uses methods that incorporate appropriate variability across the five imputations to generate valid statistical inferences about the estimated parameters.

\section{Results}

The investigated sample included a balanced proportion of participants by gender and age: mean age was 47.1 (95\% CI $46.2-$ 48.0 ); young people (18-29 years old) were $20 \%$ of the study sample. A third (35\%) of the sample reported more than 12 years of full-time education, and the majority (55\%) were in paid employment at the moment of the interview details on sampling method and on characteristics of the investigated sample are shown in Table 1.

\subsection{Lifetime prevalence estimates for eating disorders}

Lifetime prevalence estimates of anorexia nervosa, bulimia nervosa, binge ED, sub-threshold binge ED, and any binge eating were $0.48 \%, 0.51 \%, 1.12 \%, 0.72 \%$, and $2.15 \%$, respectively (Table 2 ).

Table 1

Characteristics of the sample $(N=4139)$.

\begin{tabular}{|c|c|c|}
\hline & $N$ & $\%(95 \% \mathrm{CI})$ \\
\hline \multicolumn{3}{|l|}{ Age groups } \\
\hline $18-29$ & 631 & $19.5(17.6,21.5)$ \\
\hline $30-44$ & 1339 & $30.1(28.0,32.2)$ \\
\hline $45-64$ & 1378 & $29.6(27.6,31.7)$ \\
\hline $65+$ & 791 & $20.8(19.0,22.9)$ \\
\hline \multicolumn{3}{|l|}{ Gender } \\
\hline Male & 1742 & $48.4(46.1,50.8)$ \\
\hline Female & 2397 & $51.6(49.2,53.9)$ \\
\hline \multicolumn{3}{|l|}{ Education } \\
\hline $0-12$ years & 2561 & $64.9(62.7,67.1)$ \\
\hline+12 years & 1578 & $35.1(32.9,37.3)$ \\
\hline \multicolumn{3}{|l|}{ Marital status } \\
\hline Married/cohabiting & 2729 & $66.1(63.8,68.4)$ \\
\hline Previously married & 614 & $11.1(9.7,12.7)$ \\
\hline Never married & 796 & $22.8(20.8,24.9)$ \\
\hline \multicolumn{3}{|l|}{ Geographical area } \\
\hline Rural $(<10,000)$ & 1124 & $32.5(30.2,34.9)$ \\
\hline Mid urban $(10,000-100,000)$ & 1872 & $39.6(37.3,42.0)$ \\
\hline Large urban $(>100,000)$ & 1143 & $27.9(25.7,30.2)$ \\
\hline \multicolumn{3}{|l|}{ Employment } \\
\hline Working & 2259 & $55.2(52.8,57.5)$ \\
\hline Homemaker & 79 & $2.7(2.0,3.6)$ \\
\hline Retired & 478 & $9.9(8.7,11.2)$ \\
\hline Unemployment & 900 & $24.1(22.1,26.2)$ \\
\hline Other & 423 & $8.1(6.9,9.6)$ \\
\hline \multicolumn{3}{|l|}{ Income } \\
\hline Low & 737 & $18.9(17.1,20.8)$ \\
\hline Low average & 1233 & $30.5(28.3,32.7)$ \\
\hline High average & 1425 & $34.1(31.9,36.4)$ \\
\hline High & 744 & $16.5(14.9,18.3)$ \\
\hline \multicolumn{3}{|l|}{ Country } \\
\hline Belgium & 518 & $4.1(3.5,4.9)$ \\
\hline France & 466 & $14.5(12.9,16.2)$ \\
\hline Germany & 658 & $33.6(31.5,35.8)$ \\
\hline Italy & 900 & $24.2(22.3,26.1)$ \\
\hline Netherlands & 540 & $6.7(5.8,7.6)$ \\
\hline Spain & 1057 & $16.9(15.5,18.5)$ \\
\hline
\end{tabular}


Table 2

Lifetime and 12-month prevalence estimates of eating disorders in six European countries: general results ${ }^{\mathrm{a}}$.

\begin{tabular}{|c|c|c|c|c|c|c|}
\hline & \multicolumn{2}{|c|}{ Males } & \multicolumn{2}{|c|}{ Females } & \multicolumn{2}{|c|}{ Total } \\
\hline & $N$ & $\%(95 \% \mathrm{CI})$ & $N$ & $\%(95 \% \mathrm{CI})$ & $N$ & $\%(95 \% \mathrm{CI})$ \\
\hline \multicolumn{7}{|l|}{ Lifetime prevalence } \\
\hline Anorexia nervosa & 0 & $0 \%(-)$ & 22 & $0.93 \%(0.5-1.6)$ & 22 & $0.48 \%(0.3-0.8)$ \\
\hline Bulimia nervosa & 5 & $0.12 \%(0.0-0.4)$ & 41 & $0.88 \%(0.6-1.4)$ & 46 & $0.51 \%(0.3-0.8)$ \\
\hline Binge eating disorder & 12 & $0.26 \%(0.1-0.6)$ & 64 & $1.92 \%(1.3-2.9)$ & 77 & $1.12 \%(0.8-1.6)$ \\
\hline Subthreshold binge eating disorder & 13 & $0.91 \%(0.5-1.7)$ & 16 & $0.55 \%(0.2-1.2)$ & 29 & $0.72 \%(0.4-1.2)$ \\
\hline Any binge eating disorder & 29 & $1.22 \%(0.7-2.0)$ & 112 & $3.03 \%(2.3-4.0)$ & 140 & $2.15 \%(1.7-2.8)$ \\
\hline Total: any eating disorder ${ }^{\mathrm{b}}$ & 29 & $1.22 \%(0.7-2.0)$ & 127 & $3.73 \%(2.9-4.8)$ & 155 & $2.51 \%(2.0-3.2)$ \\
\hline \multicolumn{7}{|l|}{ 12-month prevalence } \\
\hline Anorexia nervosa & 0 & $0 \%(-)$ & 1 & $0.01 \%(0.0-0.0)$ & 1 & $0 \%(0.0-0.0)$ \\
\hline Bulimia nervosa & 1 & $0.01 \%(0.0-0.1)$ & 10 & $0.29 \%(0.1-0.7)$ & 11 & $0.15 \%(0.1-0.4)$ \\
\hline Binge eating disorder & 4 & $0.07 \%(0.0-1.1)$ & 24 & $0.55 \%(0.3-1.0)$ & 28 & $0.31 \%(0.2-0.6)$ \\
\hline Subthreshold binge eating disorder & 3 & $0.19 \%(0.1-0.6)$ & 0 & $0 \%(-)$ & 3 & $0.09 \%(0.0-0.3)$ \\
\hline Any binge eating disorder & 8 & $0.26 \%(0.1-0.7)$ & 34 & $0.8 \%(0.5-1.3)$ & 42 & $0.54 \%(0.3-0.9)$ \\
\hline Total: any eating disorder ${ }^{\mathrm{b}}$ & 8 & $0.26 \%(0.1-0.7)$ & 36 & $0.84 \%(0.5-1.4)$ & 44 & $0.56 \%(0.4-0.9)$ \\
\hline
\end{tabular}

a Unweighted $n$, weighted \%.

b Any eating disorder: anorexia nervosa or bulimia nervosa or binge eating or any binge eating disorder.

Lifetime prevalence was consistently 3-8 times as high among women as men for all EDs, however defined, the only exception being sub-threshold binge ED.

Lifetime prevalence estimates were higher in France (any ED: $4.15 \%, 95 \%$ CI 2.3-7.4) in Belgium (3.54\%, 2.0-6.3) and in Italy $(3.35 \%, 2.2-5.0)$ as compared to the other three participating countries (Netherlands: $1.74 \%, 0.9-3.3$; Germany: 1.28\%, 0.8-2.1; Spain: $2.42 \%, 1.5-4.0)$. Germany and the Netherlands had the lowest estimates of lifetime prevalence for anorexia nervosa; Germany and Italy had the lowest estimates of lifetime prevalence for bulimia nervosa. Only one case of 12-month anorexia nervosa (none among males) was found in the sample. The 12-month prevalence estimates of the other four disorders were considerably lower than the lifetime estimates, although with similar sex ratios.

\subsection{Cohort effect}

We found a consistent inverse association between cohort (age at interview) and lifetime risk: younger cohort had significantly higher odds of receiving the diagnosis of an ED than the older (Table 3).

Analysis of cumulative lifetime prevalence of EDs showed that the majority of cases had their beginning between 10 and 20 years old (Fig. 1). After 20 years old, no new case of anorexia nervosa occurred, and only few cases of bulimia nervosa were reported. Binge $\mathrm{ED}$, on the other hand, continued to rise in prevalence until 40 years old, with a slight stepped additional rise after 60 years old.

\subsection{Disability and role impairment}

Twelve-month role impairment was assessed only for bulimia nervosa, binge ED and any binge eating, since the lack of cases of anorexia nervosa prevented us from investigating this area in this disorder. The majority of respondents reported at least some role impairment on WHODAS-II disability scale in at least one role domain, with similar frequency of impairment in bulimia nervosa (79.87\% [95\% CI: 43.5-95.3]), binge Ed (79.44\% [95\% CI: 42.095.4]), and any binge eating (76.67\% [95\% CI: 51.8-90.9]). However, severe role impairment was much less common, and respondents with bulimia nervosa reported slightly (non-significant) less severe role impairment (5.89\% [95\% CI: $1.2-24.9$ ]) than those with binge ED (26.9\% [95\% CI: $11.8-50.3])$ or any binge eating (17.3\% [95\% CI: 8.2-33.0]).

\subsection{Co-occurrence with other DSM-IV mental disorders}

EDs were significantly associated with a wide range of other DSM-IV disorders. In the studied sample, $42.1 \%$ of respondents with anorexia nervosa, $69.4 \%$ of those with bulimia nervosa and $62.2 \%$ of those with binge ED met criteria for at least one of the core DSM-IV disorders assessed.

Any anxiety disorder was found in 33-40\% of respondents with any diagnosed ED; mood disorders were equally highly prevalent in this group, with estimated prevalence ranging from $19 \%$ to $50 \%$ and over (data available on request).

\subsection{Service use}

A large proportion of those with a lifetime diagnosis of an ED reported service use for emotional problems (Table 4). Respondents with lifetime anorexia nervosa and bulimia nervosa were more likely to have contacted some service for emotional problems than those with sub-threshold disorders (sub-threshold binge ED and/or any binge eating). Respondents with bulimia nervosa also were

Table 3

Inter-cohort differences in lifetime risk of DSM-IV eating disorders ${ }^{\mathrm{a}}$.

\begin{tabular}{|c|c|c|c|c|c|c|c|c|c|c|}
\hline & \multicolumn{2}{|c|}{ Anorexia nervosa } & \multicolumn{2}{|c|}{ Bulimia nervosa } & \multicolumn{2}{|c|}{ Binge eating disorder } & \multicolumn{2}{|c|}{ Any binge eating } & \multicolumn{2}{|c|}{ Any eating disorder } \\
\hline & $\begin{array}{l}\text { Prevalence } \\
(95 \% \mathrm{CI})\end{array}$ & OR (95\% CI) & $\begin{array}{l}\text { Prevalence } \\
(95 \% \mathrm{CI})\end{array}$ & OR (95\% CI) & $\begin{array}{l}\text { Prevalence } \\
(95 \% \mathrm{CI})\end{array}$ & OR $(95 \% \mathrm{CI})$ & $\begin{array}{l}\text { Prevalence } \\
(95 \% \mathrm{CI})\end{array}$ & OR $(95 \% \mathrm{CI})$ & $\begin{array}{l}\text { Prevalence } \\
(95 \% \mathrm{CI})\end{array}$ & OR $(95 \% \mathrm{CI})$ \\
\hline $\begin{array}{l}\text { 18-29 } \\
\text { years }\end{array}$ & $\begin{array}{l}1.12 \%(0.5, \\
2.3)\end{array}$ & $\begin{array}{l}14.5^{\mathrm{b}}(3.48 \\
60.67)\end{array}$ & $\begin{array}{l}0.88 \%(0.4 \\
1.8)\end{array}$ & $\begin{array}{l}4.1^{\mathrm{b}}(1.16, \\
14.44)\end{array}$ & $\begin{array}{l}2.50 \%(1.3, \\
4.7)\end{array}$ & $\begin{array}{l}13.1^{\mathrm{b}}(5.07 \\
33.64)\end{array}$ & $\begin{array}{l}4.44 \%(2.9 \\
6.8)\end{array}$ & $\begin{array}{l}8.4^{\mathrm{b}}(4.04, \\
17.56)\end{array}$ & $\begin{array}{l}5.18 \%(3.5, \\
7.6)\end{array}$ & $\begin{array}{l}7.9^{\mathrm{b}}(3.89, \\
16.20)\end{array}$ \\
\hline $\begin{array}{l}30-44 \\
\text { years }\end{array}$ & $\begin{array}{l}0.58 \%(0.2, \\
1.7)\end{array}$ & $\begin{array}{l}3.0(0.77 \\
11.52)\end{array}$ & $\begin{array}{l}0.77 \%(0.4 \\
1.6)\end{array}$ & $\begin{array}{l}2.4(0.77 \\
7.32)\end{array}$ & $\begin{array}{l}1.07 \%(0.6, \\
1.8)\end{array}$ & $\begin{array}{l}3.1^{\mathrm{b}}(1.30 \\
7.45)\end{array}$ & $\begin{array}{l}2.28 \%(1.6 \\
3.3)\end{array}$ & $\begin{array}{l}2.7^{\mathrm{b}}(1.45, \\
5.05)\end{array}$ & $\begin{array}{l}2.83 \%(1.9, \\
4.1)\end{array}$ & $\begin{array}{l}2.6^{\mathrm{b}}(1.46, \\
4.57)\end{array}$ \\
\hline $\begin{array}{l}45^{+} \\
\text {years }\end{array}$ & $\begin{array}{l}0.17 \%(0.0, \\
0.6)\end{array}$ & $\begin{array}{l}1.0(1.00, \\
1.00)\end{array}$ & $\begin{array}{l}0.21 \%(0.1 \\
0.4)\end{array}$ & $\begin{array}{l}1.0(1.00, \\
1.00)\end{array}$ & $\begin{array}{l}0.61 \%(0.3, \\
1.1)\end{array}$ & $\begin{array}{l}1.0(1.00, \\
1.00)\end{array}$ & $\begin{array}{l}1.20 \%(0.7 \\
2.0)\end{array}$ & $\begin{array}{l}1.0(1.00, \\
1.00)\end{array}$ & $\begin{array}{l}1.29 \%(0.8, \\
2.1)\end{array}$ & $\begin{array}{l}1.0(1.00, \\
1.00)\end{array}$ \\
\hline
\end{tabular}

${ }^{a}$ Results based on discrete-time survival analysis with the person-year as the unit of analysis, adjusted by sex and count.

b OR based on a 0.05 level, two-sided test. The reference group is that of individuals 45 years or older. 


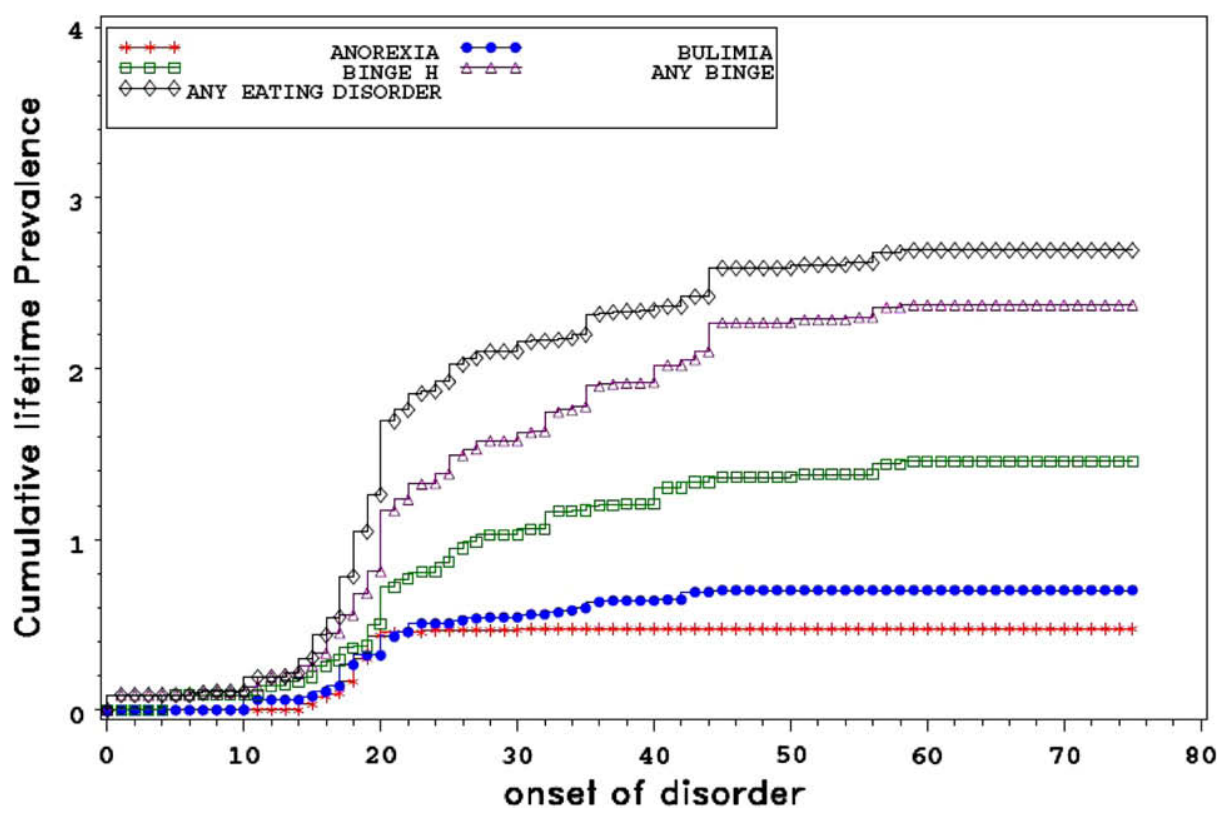

Fig. 1. Cumulative lifetime prevalence of anorexia nervosa, bulimia nervosa, binge eating disorder, and any binge eating.

more likely to have accessed the mental health sector. Respondents with binge ED accessed complementary/alternative medicine professionals (12\%) more than those with any other ED (2-8\%). As a whole, the proportion of the respondents with a lifetime diagnosis of ED who requested general medical treatment for emotional problems was low: $48 \%$ among those with bulimia nervosa, 35\% among those with anorexia nervosa, less than $30 \%$ among those with any other ED.

We found only one case of 12-month anorexia nervosa (none among males) among the respondents. In the sample, around $60 \%$ of the respondents with 12-month bulimia nervosa reported service use of some kind at the time of interview, less than $15 \%$ in the mental health sector. The corresponding proportions for binge ED were $28 \%$ and $15 \%$, respectively. As a whole, less than $40 \%$ of those with a 12 -month ED were in contact with some professional at the time of interview, and among those in contact, the majority were in contact with medical practitioners who were not mental health specialists.

\section{Discussion}

This study confirms the substantial prevalence of EDs in the general population of six major European countries. In our sample, EDs are associated to a substantial comorbidity with other mental disorders; however, the use of services among those affected people is low, with a suboptimal utilization of the mental health sector. We found lifetime prevalence estimates as low as $0.5 \%$ for both anorexia and bulimia nervosa, with significantly higher prevalence among females than males. However, the male-to-female ratio in the prevalence of these disorders (3-8) was consistently lower than those reported in clinical case surveys, where, in general, men account for less than $10 \%$ of cases (Fairburn and Beglin, 1990; Hoek and Van Hoeken, 2003). As a whole, these estimates, as those of population-based studies, must be considered conservative, since they involve very small numbers of cases of men with EDs.

Comparison with past investigations is difficult: to date no laboratory test can identify these diagnostic entities, and clinical interviews still represent the best diagnostic tool. In the NEMESIS study, which used a previous version of CIDI, lifetime prevalence for anorexia and bulimia nervosa in Netherlands were twice as high as those presently reported (Bijl et al., 1998). In the Sesto Fiorentino study, based on the Mini International Neuropsychiatric Interview administered to 2355 respondents representative of the population aged above 14 years living in Sesto Fiorentino (near Florence, Italy), the estimated lifetime prevalence was $0.42 \%$ for anorexia nervosa, $0.32 \%$ for bulimia nervosa, and $0.32 \%$ binge $E D$, with the majority of cases among females (Faravelli et al., 2006). In that study, however, a much higher proportion of subjects (90-100\%) meeting the criteria for any ED consulted their general practitioner than in this study, and more than $50 \%$ contacted a psychiatrist or a psychologist for their disorder.

Past studies which included the adolescent population found higher prevalence for bulimia nervosa than in our study: from $1.1 \%$, in a 15-17 years old Italian sample of school-aged students (Santonastaso et al., 1996), to $1.2 \%$ in Sweden (Råstam et al., 1989). However, prevalence similar, or lower than ours, have also been reported in samples including adolescent respondents: from $0.2 \%$ among 2544 students aged $13-18$ in the USA (Whitaker et al., 1990), to $0.5 \%$ in Hong-Kong ( $N=1020$ students, $17-24$ years old) (Lee, 1993).

Our data are consistent with past investigations pointing to an increase in the prevalence of EDs across time, particularly in the second half of the 20th century (Bulik et al., 2006; Hoek and Van Hoeken, 2003; Hudson et al., 2007; Kendler et al., 1991). Nevertheless, higher lifetime prevalence in the youngest cohort of cases meeting DSM-IV criteria for anorexia or bulimia nervosa should be taken with caution: recall of early experiences may diminish with age, so any retrospective assessment may overestimate the magnitude of cohort effect (Hudson et al., 2007). Moreover, currently EDs receive much more public attention, particularly in the media, than in the past, and this may have created greater attention, and so greater recall, for the symptoms indicative of these disorders in the younger than in the older cohorts. Then, EDs bear a very high risk of premature mortality (Patton, 1988; Sullivan, 1995), and this may have contributed to unequal prevalence by cohort. Only prospective studies can really track cohort effects across time. Indeed, consecutive population surveys have 


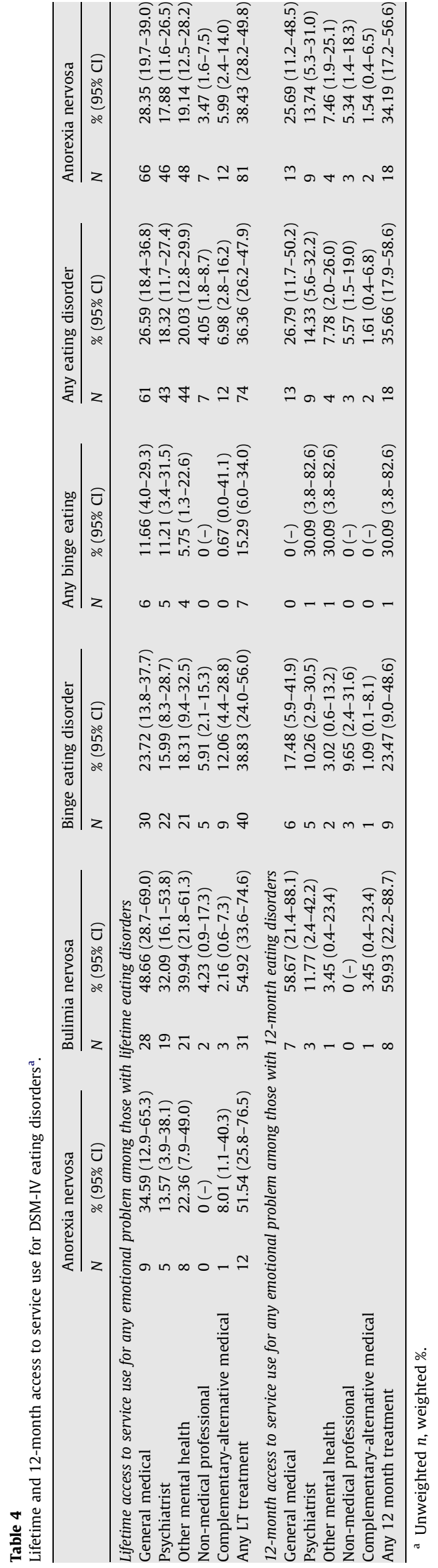

shown that in recent years (1995-2005) the increase has been real, principally in the spectrum of eating disorders not otherwise specified (EDNOS) (Hay et al., 2008).

We found role impairment to be a rather widespread occurrence in EDs: although we were unable to investigate this issue in anorexia nervosa, since only one 12 -month case was identified with that diagnosis, nevertheless more than $2 / 3$ of those with EDs had at least some role impairment in at least one role domain. Severe role impairment, however, was much less frequent, with cases with bulimia nervosa reporting less often severe impairment on the WHODAS-II than those with binge ED, a pattern which is the reverse of that found by Hudson and co-workers in the NCS-R (Hudson et al., 2007). The low number of individuals with the disorders and the use of an instrument more stringent for case definition, might explain this discrepancy.

\subsection{Eating disorders, comorbidity and use of services}

In the sample, more than half of the cases with any ED reported some lifetime comorbid mental disorder. This finding is consistent with past survey showing a high level of comorbidity in both clinical samples (Godart et al., 2002; Halmi et al., 2005; Hudson et al., 1987; Kaye et al., 2004; McElroy et al., 2005; Milos et al., 2003), and in population-based studies (Bulik et al., 2002; Bushnell et al., 1990; Garfinkel et al., 1995, 1996; Jacobi et al., 2004; Vollrath et al., 1992) of anorexia nervosa, bulimia nervosa and binge ED. The reason for this high level of comorbidity is not known, but genetic factors are likely to play an important role, at least for the cooccurrence of EDs with mood disorders (Ribasés et al., 2008; Wade et al., 2000; Walters et al., 1992).

However, despite high comorbidity with other mental disorders, which should enhance the search for new treatments (Jacobi et al., 2004; Milos et al., 2003), only a scant proportion of cases sought contact with mental health services for emotional problems: failure in recognizing ED in the medical setting (Hoek, 1991; Keski-Rahkonen et al., 2007), and the egosyntonic nature of symptoms in most cases might contribute to the low degree of service utilization among people with EDs (Fairburn and Harrison, 2003; Halmi et al., 2005).

\subsection{Course of eating disorders}

As in the NCS-R study (Hudson et al., 2007), we found that lifetime prevalence of EDs is substantially higher than the 12-month prevalence, suggesting these disorders do not necessarily display a chronic and unremitting course: a large fraction of those who met the criteria for lifetime diagnosis of an ED did not report current symptoms of the disorder in the most recent 12-month interval. Recent studies found a $75 \%$ of recovery rate in anorexia nervosa, although only less than $50 \%$ of diagnosed cases were totally asymptomatic (60\% in bulimia nervosa) (Jäger et al., 2004; Wade et al., 2006). The introduction of specialized care units for these disorders in some countries seems to have improved patients' survival, particularly in anorexia nervosa (Lindblad et al., 2006; Papadopoulos et al., 2009). However, it cannot be ruled out that, due to the study method, the most severe cases of anorexia and bulimia nervosa were not included in the study sample, since they were hospitalized or unwilling to participate in an investigation on emotional problems.

\subsection{Nosological relevance of binge eating disorders}

As found in the NCS-R study (Hudson et al., 2007), binge ED is a rather chronic and stable condition, associated to an even higher chance of severe role impairment as compared to bulimia nervosa. Binge ED was more common than the two currently recognized 
EDs (e.g., anorexia and bulimia nervosa) in all six investigated countries, also showing a substantial comorbidity with other DSM-IV mental disorders, particularly anxiety and mood disorders. These findings seem to point to the importance of binge ED as an autonomous ED, in need of appropriate public health attention. Binge ED has a role in the development of obesity (Yanovski, 2003): indeed, recent consecutive population surveys found that increasing prevalence of binge eating behaviours was associated to a faster increasing comorbidity with obesity (Darby et al., 2009).

\subsection{Limitations of the study}

Our estimates should be considered lower-bound estimates of EDs prevalence in the general population: our sample did not include people younger than 18 years old, who are those more likely to develop symptoms of EDs.

The exclusion of people under 18 is probably the main reason for the identification of just one case of anorexia nervosa in the last 12-months in our sample; another reason is the small sample size of those in the immediately subsequent high-risk age band, aged 18-25 (on average, $N=100$ by country). Although great care has been put in the study design and in data collection, these limitations make the study samples not closely representative of those who can be seen in clinical settings with EDs.

These limitations may also contribute to the contradictory finding of a similar prevalence between anorexia and bulimia nervosa. In most studies, the prevalence of bulimia nervosa is about twice as much as that of anorexia nervosa. In any event, other studies have reported similar prevalence for both conditions (Råstam et al., 1989; Whitaker et al., 1990).

Moreover, CIDI questions did not exactly match DSM-IV criteria for EDs, diagnoses were based on lay interviews, and lifetime information was assessed retrospectively. In addition, the most severe cases of these disorders, those with severe forms of anorexia nervosa or with severe psychiatric comorbidity in bulimia nervosa, are both conditions likely to lead to hospitalization or to residential care, and these settings were not included in the general population sample to be recruited for interview. Another reason of low prevalence in this study might be the stigma associated to the condition: in non-clinical samples, measures of social desirability are negatively related to the self-reporting of ED symptoms (Miotto et al., 2002).

Willingness to participate, also, may have been uneven between cases and non-cases: patients with anorexia and bulimia nervosa have high dropout rates (Bacaltchuk et al., 2000; Halmi et al., 2005), and it cannot be excluded that they are also less likely to participate in a survey on emotional problems. Finally, because of the use of a hierarchical algorithm in making the diagnoses, we were unable to address the issue of diagnostic crossover, which is relatively frequent in EDs (Eddy et al., 2008; Tozzi et al., 2005).

Despite these limitations, the study confirms the substantial prevalence of EDs in the general population. It still has to be proven whether early diagnostic identification and access to specialized care can reduce the burden caused by these disorders (StriegelMoore et al., 2008).

\section{Conflict of interest statement}

To the best of our knowledge, no conflict of interest is foreseeable concerning the data and results described in this article.

\section{Funding source}

This project was funded by the European Commission (Contract QLG5-1999-01042); the Piedmont Region (Italy); Fondo de Inves- tigacion Sanitaria, Instituto de Salud Carlos III, Spain (FIS 00 0028); Ministerio de Ciencia Y Tecnologia, Spain (SAF 2000-158CE); Department de Sanitat, Generalitat de Catalunya, Spain; other local agencies and by an unrestricted educational grant from GlaxoSmithKline.

\section{Contributors}

The ESEMeD-WMH Investigators are: Jordi Alonso, Matthias Angermeyer, Sebastian Bernert, Ronny Bruffaerts, Traolach S. Brugha, Giovanni de Girolamo, Ron de Graaf, Koen Demyttenaere, Isabelle Gasquet; Josep Maria Haro, Steven J. Katz; Ronald C. Kessler, Viviane Kovess, Jean Pierre Lépine, Johan Ormel, Gabriella Polidori, and Gemma Vilagut.

Gemma Vilagut did all statistical analyses.

As for the manuscript, the authors, all co-jointly had the idea and wrote, revised and approved the final manuscript.

\section{Acknowledgement}

This project was funded by the European Commission (Contract QLG5-1999-01042, SANCO 2004123), the Piedmont Region (Italy), Fondo de Investigación Sanitaria, Instituto de Salud Carlos III, Spain (FIS 00/0028), Ministerio de Ciencia y Tecnología, Spain (SAF 2000-158-CE), Department de Salut, Generalitat de Catalunya, Spain, and other local agencies and by an unrestricted educational grant from GlaxoSmithKline. ESEMeD is carried out in conjunction with the World Health Organization World Mental Health (WMH) Survey Initiative. We thank very much the WMH staff for assistance with instrumentation, fieldwork, and data analysis.

\section{Appendix A. Supplementary data}

Supplementary data associated with this article can be found, in the online version, at doi:10.1016/j.jpsychires.2009.04.003.

\section{References}

American Psychiatric Association. Diagnostic and statistical manual of mental disorders (DSM-IV). 4th ed. Washington (DC): American Psychiatric Association; 1994.

Bacaltchuk J, Hay P, Mari JJ. Antidepressants versus placebo for the treatment of bulimia nervosa: a systematic review. Australian and New Zealand Journal of Psychiatry 2000;34:310-7.

Bijl RV, Ravelli A, van Zessen G. Prevalence of psychiatric disorder in the general population: results of the Netherlands Mental Health Survey and Incidence Study (NEMESIS). Social Psychiatry and Psychiatric Epidemiology 1998;33:587-95.

Buist-Bouwman MA, De Graaf R, Vollebergh WA, Alonso J, Bruffaerts R, Ormel J. Functional disability of mental disorders and comparison with physical disorders: a study among the general population of six European countries. Acta Psychiatrica Scandinavica 2006;113:492-500.

Bulik CM, Sullivan PF, Kendler KS. Medical and psychiatric morbidity in obese women with and without binge eating. International Journal of Eating Disorders 2002;32:72-8.

Bulik CM, Sullivan PF, Tozzi F, Furberg H, Lichtenstein P, Pedersen NL. Prevalence, Heritability, and Prospective Risk Factors for Anorexia Nervosa. Archives of General Psychiatry 2006;63:305-12.

Bushnell JA, Wells JE, Hornblow AR, Oakley-Browne MA, Joyce P. Prevalence of three bulimia syndromes in the general population. Psychological Medicine 1990;20:671-80.

Chwastiak LA, Von Korff M. Disability in depression and back pain: evaluation of the World Health Organization Disability Assessment Schedule (WHO DAS II) in a primary care setting. Journal of Clinical Epidemiology 2003;56:507-14.

Cox DR, Oakes D. Analysis of survival data. London: Chapman and Hall; 1984.

Darby A, Hay P, Mond J, Quirk F, Buttner P, Kennedy L. The rising prevalence of comorbid obesity and eating disorder behaviors from 1995 to 2005 . International Journal of Eating Disorders 2009;42:104-8.

Eddy KT, Dorer DJ, Franko DL, Tahilani K, Thompson-Brenner H, Herzog DB. Diagnostic crossover in anorexia nervosa and bulimia nervosa: implications for DSM-V. American Journal of Psychiatry 2008;165:245-50. 
ESEMeD/MHEDEA 2000 Investigators. Prevalence of mental disorders in Europe: results from the European Study of the Epidemiology of Mental Disorders (ESEMeD) project. Acta Psychiatrica Scandinavica 2004a;109(Suppl. 420):21-7.

ESEMeD/MHEDEA 2000 Investigators. Sampling and methods of the European study of epidemiology of mental disorders (ESEMeD) project. Acta Psychiatrica Scandinavica 2004b;109(suppl. 420):8-20.

Fairburn CG, Beglin SJ. Studies of the epidemiology of bulimia nervosa. American Journal of Psychiatry 1990;147:401-8.

Fairburn CG, Harrison PJ. Eating disorders. Lancet 2003;361:407-16.

Faravelli C, Ravaldi C, Truglia E, Zucchi T, Cosci F, Ricca V. Clinical epidemiology of eating disorders: results from the Sesto Fiorentino study. Psychotherapy and Psychosomatics 2006;75:376-83.

Favaro A, Ferrara S, Santonastaso P. The spectrum of eating disorders in young women: a prevalence study in a general population sample. Psychosomatics Medicine 2004;65:701-8.

Garfinkel PE, Lin E, Goering P, Spegg C, Goldbloom DS, Kennedy S, et al. Bulimia nervosa in a Canadian community sample: prevalence and comparison subgroups. American Journal of Psychiatry 1995;152:1052-8.

Garfinkel PE, Lin E, Goering C, Spegg D, Goldbloom D, Kennedy S. Should amenorrhoea be necessary for the diagnosis of anorexia nervosa? Evidence from a Canadian community sample. British Journal of Psychiatry 1996;168:500-6.

Godart NT, Flament MF, Perdereau F, Jeammet P. Comorbidity between eating disorders and anxiety disorders: a review. International Journal of Eating Disorders 2002;32:253-70.

Halmi KA, Agras WS, Crow S, Mitchell J, Wilson GT, Bryson SW, et al. Predictors of treatment acceptance and completion in anorexia nervosa: implications for future study designs. Archives of General Psychiatry 2005;62:776-81.

Haro JM, Arbabzadeh-Bouchez S, Brugha TS, de Girolamo G, Guyer ME, Jin R. Et al. Concordance of the Composite International Diagnostic Interview Version 3.0 (CIDI 3.0) with standardized clinical assessments in the WHO World Mental Health surveys. International Journal of Methods in Psychiatric Research 2006;15:167-80.

Hay PJ, Mond J, Buttner P, Darby A. Eating disorder behaviors are increasing: findings from two sequential community surveys in South Australia. PLoS ONE 2008;3:e1541. doi:10.1371/journal.pone.0001541.

Hoek HW. The incidence and prevalence of anorexia nervosa and bulimia nervosa in primary care. Psychological Medicine 1991;21:455-60.

Hoek HW, van Hoeken D. Review of the prevalence and incidence of eating disorders. International Journal of Eating Disorders 2003;34:383-96.

Hudson JI, Pope Jr HG, Yurgelun-Todd D, Jonas JM, Frankenburg FR. A controlled study of lifetime prevalence of affective and other psychiatric disorders in bulimic outpatients. American Journal of Psychiatry 1987;144:1283-7.

Hudson JI, Hiripi E, Pope Jr HG, Kessler RC. The prevalence and correlates of eating disorders in the National Comorbidity Survey Replication. Biological Psychiatry 2007;61:348-58.

Jacobi F, Wittchen H-U, Hölting C, Höfler M, Pfister H, Müller N, et al. Prevalence, comorbidity and correlates of mental disorders in the general population: results from the German Health Interview and Examination Survey (GHS). Psychological Medicine 2004;34:597-611.

Jäger B, Liedtke R, Lamprecht F, Freyberger $\mathrm{H}$. Social and health adjustment of bulimic women 7-9 years following therapy. Acta Psychiatrica Scandinavica 2004;110:138-45.

Kaye WH, Bulik CM, Thornton L, Barbarich N, Master K. Comorbidity of anxiety disorders with anorexia and bulimia nervosa. American Journal of Psychiatry 2004;161:2215-21.

Kendler KS, MacLean C, Neale M, Kessler R, Heath A, Eaves L. The genetic epidemiology of bulimia nervosa. American Journal of Psychiatry 1991;148:1627-37.

Keski-Rahkonen A, Hoek HW, Susser ES, Linna MS, Sihvola E, Raevuori A, et al. Epidemiology and course of anorexia nervosa in the community. American Journal of Psychiatry 2007;164:1259-65.

Kessler RC, Ustun TB. The World Mental Health (WMH) Survey Initiative Version of the World Health Organization (WHO) Composite International Diagnostic Interview (CIDI). International Journal of Methods in Psychiatric Research 2004;13:93-121.

Kinzl JF, Traweger C, Trefalt E, Mangweth B, Biebl W. Binge eating disorder in males: a population-based investigation. Eating and Weight Disorders 1999;4:169-74.

LaVange L, Stearns S, Lafata J, Koch G. Innovative strategies using SUDAAN or analysis of health surveys with complex samples. Statical Methods in Medical Research 1996;5:311-29.

Lee S. How abnormal is the desire for slimness? A survey of eating attitudes and behaviour among Chinese undergraduates in Hong Kong. Psychological Medicine 1993;23:437-51.

Lindblad F, Lindberg L, Hjern A. Improved survival in adolescent patients with anorexia nervosa: a comparison of two Swedish national cohorts of female inpatients. American Journal of Psychiatry 2006;163:1433-5.

Little RJA, Rubin DB. Statistical analysis with missing data. 2nd ed. New York: John Wiley and Sons Inc.; 1987.
McElroy SL, Kotwal R, Keck Jr PE, Akiskal HS. Comorbidity of bipolar and eating disorders: distinct or related disorders with shared dysregulations? Journal of Affective Disorders 2005;86:107-27.

Milos GF, Spindler AM, Buddeberg C, Crameri A. Axes I and II comorbidity and treatment experiences in eating disorder subjects. Psychotherapy and Psychosomatics 2003;72:276-85.

Miotto P, De Coppi M, Frezza M, Rossi M, Preti A. Social desirability and eating disorders. A community study of an Italian school-aged sample. Acta Psychiatrica Scandinavica 2002;105:372-7.

Miotto P, De Coppi M, Frezza M, Preti A. The Spectrum of eating disorders prevalence in an area of Northeast Italy. Psychiatry Research 2003;119:145-54

Papadopoulos FC, Ekbom A, Brandt L, Ekselius L. Excess mortality, causes of death and prognostic factors in anorexia nervosa. British Journal of Psychiatry 2009;194:10-7.

Patton GC. Mortality in eating disorders. Psychological Medicine 1988;18:947-51.

Patton GC, Selzer R, Coffey C, Carlin JB, Wolfe R. Onset of adolescent eating disorders: population based cohort study over 3 years. BMJ 1999;318:765-8.

Råstam M, Gillberg C, Garton M. Anorexia nervosa in a Swedish urban region. A population-based study. British Journal of Psychiatry 1989;155:642-6.

Reichborn-Kjennerud T, Bulik C, Tambs K, Harris J. Genetic and environmental influences on binge eating in the absence of compensatory behaviours: a population-based twin study. International Journal of Eating Disorders 2004;36:307-14.

Research Triangle Institute. SUDAAN Language Manual, Release 9.0. Research Triangle Park (NC): Research Triangle Institute; 2004.

Ribasés M, Fernández-Aranda F, Gratacòs M, Mercader JM, Casasnovas C, Núñez A et al. Contribution of the serotoninergic system to anxious and depressive traits that may be partially responsible for the phenotypical variability of bulimia nervosa. Journal of Psychiatric Research 2008;42:50-7.

Santonastaso P, Zanetti T, Sala A, Favaretto G, Vidotto G, Favaro A. Prevalence of eating disorders in Italy: a survey on a sample of 16-year-old female students. Psychotherapy and Psychosomatics 1996;65:158-62.

Singer JD, Willett JB. It's about time: using discrete-time survival analysis to study duration and the timing of events. Journal of Educational Statistics 1993;18:155-95.

Spitzer RL, Devlin M, Walsh BT, Hasin D, Wing R, Marcus M, et al. Binge eating disorder: a multi-site field trial of the diagnostic criteria. International Journal of Eating Disorders 1992;11:191-203.

Striegel-Moore RH, DeBar L, Wilson GT, Dickerson J, Rosselli F, Perrin N, et al. Health services use in eating disorders. Psychological Medicine 2008;38:1465-74.

Sullivan PF. Mortality in anorexia nervosa. American Journal of Psychiatry 1995;152:1073-4.

Tozzi F, Thornton LM, Klump KL, Fichter MM, Halmi KA, Kaplan AS, et al. Symptom fluctuation in eating disorders: correlates of diagnostic crossover. American Journal of Psychiatry 2005;162:732-40.

Vega Alonso AT, Rodríguez MAR, Alonso JEL, Carretero GR, Martín MF. Eating disorders. Prevalence and risk profile among secondary school students. Social Psychiatry and Psychiatric Epidemiology 2005;40:980-7.

Vollrath M, Koch R, Angst J. Binge eating and weight concerns among young adults. Results from the Zurich cohort study. British Journal of Psychiatry 1992;160:498-503

Von Korff M, Crane PK, Alonso J, Vilagut G, Angermeyer MC, Bruffaerts R, et al Modified WHODAS-II provides valid measure of global disability but filter items increased skewness. Journal of Clinical Epidemiology 2008(July) [Epub ahead of print].

Wade TD, Bulik CM, Neale M, Kendler KS. Anorexia nervosa and major depression: shared genetic and environmental risk factors. American Journal of Psychiatry 2000;157:469-71.

Wade TD, Bergin JL, Tiggemann M, Bulik CM, Fairburn CG. Prevalence and long-term course of lifetime eating disorders in an adult Australian twin cohort. Australian and New Zealand Journal of Psychiatry 2006;40:121-8.

Walters EE, Kendler KS. Anorexia nervosa and anorexic-like syndromes in a population-based female twin sample. American Journal of Psychiatry 1995;152:64-71.

Walters EE, Neale MC, Eaves LJ, Heath AC, Kessler RC, Kendler KS. Bulimia nervosa and major depression: a study of common genetic and environmental factors. Psychological Medicine 1992;22:617-22.

Whitaker A, Johnson J, Shaffer D, Rapoport JL, Kalikow K, Walsh BT, et al. Uncommon troubles in young people: prevalence estimates of selected psychiatric disorders in a nonreferred adolescent population. Archives of General Psychiatry 1990;47:487-96

World Health Organization. The ICD-10 classification of mental and behavioural disorders. Geneva: World Health Organization; 1992.

Williamson DA, Gleaves DH, Stewart TM. Categorical versus dimensional models of eating disorders: an examination of the evidence. International Journal of Eating Disorders 2005;31:1-10.

Yanovski SZ. Binge eating disorder and obesity in 2003: could treating an eating disorder have a positive effect on obesity epidemic? International Journal of Eating Disorders 2003;34:S117-20. 